\title{
Insects and the city: what island biogeography tells us about insect conservation in urban areas
}

\author{
S. Fattorini ${ }^{1,2}$ \\ ${ }^{1} \mathrm{CE} 3 \mathrm{C}$ - Centre for Ecology, Evolution and Environmental Changes/Azorean Biodiversity Group and \\ Universidade dos Açores, Departamento de Ciências Agrárias, 9700-042 Angra do Heroísmo, Azores, Portugal \\ ${ }^{2}$ Department of Life, Health and Environmental Sciences, University of L'Aquila, Via Vetoio, Coppito, \\ 67100 L'Aquila, Italy
}

Correspondence to: S. Fattorini (simone.fattorini@gmail.com)

Received: 24 September 2015 - Revised: 26 December 2015 - Accepted: 1 February 2016 - Published: 9 February 2016

\begin{abstract}
Habitat fragmentation caused by urbanization is considered a prominent threat to biodiversity. Urban development creates a mosaic of natural fragments which can be occupied by organisms able to survive in small spaces. These fragments are a set of habitat islands separated by less suitable non-native habitats. Because of their isolation, communities of urban green spaces can be investigated using hypotheses developed in island biogeography. The "equilibrium theory of island biogeography" (ETIB) allows the formulation of some predictions about how various characteristics of green spaces (such as their area, shape, level of isolation, environmental heterogeneity, age) should influence species richness. Many studies found support for ETIB predictions, but results varied considerably according to the species' sensitivity to patch size, matrix characteristics, and history of the city. In some cases ETIB predictions were falsified. These contrasting results warn against making generalizations on conservation strategies only based on ETIB models. On the other hand, the ETIB may represent a useful framework for urban conservation, especially for small animals like insects, if the roles of other factors, such as the surrounding landscape, the specific needs of the species under study, and the history of the urbanization process, are taken into account.
\end{abstract}

\section{Introduction}

From the perspective of the organisms that live in urban green spaces (e.g. parks, wetlands, gardens, backyards, green roofs, green gardens), the urban environment can look like a set of habitat islands, which form the green infrastructure, separated by inhospitable or less suitable environments (e.g. builtup areas, industrial sites, parking lots, streets). Thus, biotic communities of urban green spaces should have population dynamics similar to those of islands.

Since their inception, biodiversity studies in urban areas have been inspired by the theory of island biogeography (e.g. Faeth and Kane, 1978). In particular, the "equilibrium theory of island biogeography" (ETIB), developed by MacArthur and Wilson in the 1960s, was at the base of the principles of reserve design initially proposed by Diamond in the 1970s (see Triantis and Bhagwat, 2011, for a review) and can be also applied to urban green spaces. The ETIB allows the formulation of some explicit predictions about the influence of area, shape, environmental diversity, level of isolation, and other characteristics of urban green spaces on species richness and extinction levels.

\section{Predictions about species richness}

On the basis of principles derived, more or less directly, from the ETIB, we can formulate some predictions about how certain characteristics of urban green spaces can affect species richness. For details about the rationale of each prediction, see Fattorini (2014a).

- Prediction 1: Species richness should increase with area size, because larger islands will tend (i) to support larger populations (area per se hypothesis), (ii) to have higher habitat diversity (habitat diversity hypothesis) and/or (iii) to be larger targets for potential colonists 
(passive sampling hypothesis) (see, for example, Murgui, 2007).

- Prediction 2: Species richness should increase with circularization of area shape because a more rounded shape should reduce edge effects.

- Prediction 3: Species richness should be inversely related with isolation, because colonization rates decrease with isolation.

- Prediction 4: Species richness should decrease from periphery to city centre as a result of increasing distance from natural or semi-natural landscapes that may serve as species sources.

- Prediction 5: Species richness should increase with the extent of native habitats within each green space, because larger fragments have a larger probability of including remnants of native habitats.

- Prediction 6: Species richness should increase with circularization of native habitat fragments. Not all the surface of an urban green space may be suitable for an insect. Thus, more than the shape of the overall green spaces, it is that of natural habitats within there that may be important for insect conservation.

\section{Predictions about species extinction}

Because urbanization tends to make green spaces smaller, more isolated, and less hospitable, urban green spaces are not at equilibrium; rather, species extinction rates are expected to be generally higher than colonization rates (Fattorini, 2011a). Thus, most of urban green spaces should conform to "relaxation" dynamics, which allows the formulation of the following predictions about species loss.

- Prediction 7: Extinction levels should correlate negatively with area size, because larger areas support larger populations that are less vulnerable to demographic oscillations, genetic drift, inbreeding, and reduced heterozygosis.

- Prediction 8: Extinction levels should correlate negatively with circularization of green spaces, because more circular shapes should promote conspecific interaction.

- Prediction 9: Extinction levels should correlate negatively with proximity to other green spaces, because (i) where there is more urban green space, there is more likely to be enough suitable environment to sustain a meta-population; (ii) higher connectivity reduces the effects of genetic isolation, and (iii) small green spaces, even if unable to sustain a stable population of a given species, may sustain individuals that are dispersing towards more suitable areas.
- Prediction 10: Extinction levels should correlate negatively with distance to the city centre because (i) human disturbance is reduced in more peripheral sectors of a city, and (ii) more peripheral green spaces are closer to the areas that are a source of immigrants and can benefit from rescue effects.

- Prediction 11: Extinction levels should correlate negatively with the extent of native habitats, because larger habitats increase long-term viability of populations.

- Prediction 12: Extinction levels should correlate negatively with circularization of the shape of native habitats, because more rounded shapes should reduce the impact of edge effects.

\section{Empirical evidence}

A number of urban studies found support for ETIB predictions, but results varied considerably according to the study systems. Moreover, available research is mostly limited to pattern description (Predictions 1-6), whereas studies on extinction rates are virtually lacking, probably because of difficulties in obtaining information on species loss. The most documented pattern is an increase in insect species richness (or other measures of diversity) with area of urban green spaces as predicted by Prediction 1 (Jones and Leather, 2012; see also Table 1). However, in some cases a positive correlation was found for rural sites, but not for the urban ones, or was definitely absent (Jones and Leather, 2012). In general, if the aim is to maximize species richness, larger green spaces should be preferred to smaller spaces (everything else being equal). However, if the total area that can be preserved is a fixed amount, and the focus of conservation is on imperiled species, the idea that a single large reserve should be preferred to several small ones may be questioned. This is a long disputed issue in the field of conservation biology known as the SLOSS ("single large or several small") debate (see Godefroid and Koedam, 2003, for a discussion regarding urban green spaces). For example, a study conducted on the tenebrionid beetles of Rome (Fattorini, 2014b) revealed that the conservation importance of urban green spaces cannot be predicted on the basis of their geographical characteristics, but must be established on the basis of which species they actually host. Moreover, much of the effect of area might be a consequence of the fact that larger areas have a greater habitat heterogeneity, which might be the "true" driver of species richness (see Fattorini et al., 2015). For example, a study of butterflies inhabiting urban green spaces in Prague (Konvicka and Kadlec, 2011) showed that species diversity tends to increase with habitat heterogeneity.

In the case of urban green spaces, much attention has been focused on the extent and quality of a particular "habitat": the native forests (see, for example, references give in Table 1 for Prediction 5). However, studies supporting the importance of 
Table 1. Examples of studies supporting predictions about species richness in urban green spaces.

\begin{tabular}{|c|c|c|}
\hline Prediction & $\begin{array}{l}\text { Level of support in } \\
\text { literature }\end{array}$ & Examples of references \\
\hline $\begin{array}{l}\text { 1. Species richness should increase } \\
\text { with area size, }\end{array}$ & Strong & $\begin{array}{l}\text { Faeth and Kane (1978), Miyashita et al. (1998), Bolger et } \\
\text { al. (2000), Koivula and Vermeulen (2005), Knapp et al. (2008), } \\
\text { Saarinen et al. (2005), Soga et al. (2013) }\end{array}$ \\
\hline $\begin{array}{l}\text { 2. Species richness should increase } \\
\text { with circularization of area shape. }\end{array}$ & Good & Yamaura et al. (2008), Kotze et al. (2012) \\
\hline $\begin{array}{l}\text { 3. Species richness should be } \\
\text { inversely related with isolation. }\end{array}$ & Good & $\begin{array}{l}\text { Davis (1979), Hardy and Dennis (1999), Magura et al. (2001), } \\
\text { Weller and Ganzhorn, (2004), Sadler et al. (2006), Small et } \\
\text { al. (2006), Croci et al. (2008) }\end{array}$ \\
\hline $\begin{array}{l}\text { 4. Species richness should decrease } \\
\text { from periphery to city centre. }\end{array}$ & $\begin{array}{l}\text { Strong for native } \\
\text { species }\end{array}$ & $\begin{array}{l}\text { Blair (1999). See also Jones and Leather (2012) and Adler and } \\
\text { Tanner (2013) for references. }\end{array}$ \\
\hline $\begin{array}{l}\text { 5. Species richness should increase } \\
\text { with the extent of native habitats } \\
\text { within each green space. }\end{array}$ & $\begin{array}{l}\text { Variable according to } \\
\text { species' ecology }\end{array}$ & Konvicka and Kadlec (2011), Kotze et al. (2012) \\
\hline $\begin{array}{l}\text { 6. Species richness should increase } \\
\text { with circularization of native habi- } \\
\text { tat fragments. }\end{array}$ & $\begin{array}{l}\text { Variable according to } \\
\text { species' ecology }\end{array}$ & Sisk et al. (1997), Yamaura et al. (2008), Kotze et al. (2012) \\
\hline
\end{tabular}

forest habitats were conducted in North American and in central and northern European cities that grew into agricultural and forested landscapes. By contrast, a study conducted in a Mediterranean context, where most of the species that composed the "original" insect fauna were probably associated more with open habitats than forests (Fattorini, 2011b, 2013), revealed an opposite pattern. These results warn against the risk of generalizations about the conservation importance of particular biotopes as "key habitats" and call for the need of studies that take into account local ecological settings. In general, as observed for rare plant species (Parker, 2012), even small green spaces may have an important role for insect conservation in urban areas (see Fattorini, 2011b).

A study of urban tenebrionids in Rome (Fattorini, 2014a) also showed a negative effect of circularization of forest fragments on species richness, which is opposite to Prediction 6. Because urban green spaces tend to deviate substantially from a circular shape, this sounds like good news. Circularization is inversely related to ecotonal development. Thus, this result also contrasts with previous findings on the negative effects of edge development on insect diversity (see, for example, references given in Table 1 for Prediction 2). However, ecotonal development may have negative effects on insects that are associated with forest habitats (and particularly on interior species), but a positive one on open-habitat and forest generalist species. As a matter of fact, results that supported the importance of circularization were obtained from cities where the investigated insects were mainly forest species (e.g. Kotze et al., 2012).

As regards Predictions 3 and 4, isolation of green spaces has been shown to affect negatively insect diversity and abun- dance in various contexts, as a consequence of the fact that the built-up matrix is generally inhospitable and difficult to cross for most species (see Table 1). However, response of arthropod species to isolation depends on their ability to cross the matrix. Thus, in contrast with Prediction 3, which is well supported in literature (see Table 1), connectivity did not enhance tenebrionid diversity of green spaces, probably because of the substantially relictual character of their urban communities. Isolation can have a reduced impact also for very mobile species, but for opposite reasons. Insects able to disperse even across inhospitable environments to reach isolated habitat islands may be more affected by habitat quality than isolation (Angold et al., 2006). Thus, promoting connectivity among urban green spaces by corridors or networks of green spaces that may act as stepping stones may be a useful strategy for insect conservation, but it is important that a relatively high habitat quality is preserved, at least in the largest green spaces. Finally, many studies on the urban-rural gradient identified negative trends (see, for example, references given in Table 1 for Prediction 4), which may indirectly support also Prediction 10. However, other studies found a peak of insect species richness at the gradient mid-point (Jones and Leather, 2012) and no urban-rural gradient effect was found for Rome tenebrionids (Fattorini, 2014a).

With respect to the impact of green space characteristics on insect extinction rates, the only study that explicitly addressed this issue is one conducted on the tenebrionid beetles of Rome (Fattorini, 2014a). Here it was found that larger urban green spaces present lower extinction levels, thus supporting Prediction 7, but also that the percentage of forested area had a negative effect on species richness and species 
persistence (in contrast with Prediction 11). This negative effect, as well as a lack of green space and forest shape effects on species extinction (in contrast with Predictions 8 and 12), may be explained by the low number of truly forest interior species among tenebrionids. However, in accordance with Prediction 9, early (pre-1960) tenebrionid extinctions were promoted by increasing mean distance between green spaces, which suggests that isolation has a detrimental effect on species persistence (Fattorini, 2014a).

\section{Conclusions and future work}

Contrasting results provided by empirical studies worldwide warn against making generalizations on urban diversity patterns and conservation strategies based on ETIB models. On the other hand, the ETIB may represent a useful framework for conservation studies in urban areas, especially for small animals like insects, if the roles of other factors, such as the surrounding landscape, the specific needs of the species under study, and the history of the urbanization process, are taken into account.

Currently available studies are mostly based on pattern description, whereas the possible relationships between green shape characteristics and temporal trends in species extinction remain largely unexplored. This is probably due to the assumed lack of data to reconstruct temporal trends. However, results based on the use of museum data from Rome (Fattorini, 2011a) suggest that a similar approach could be attempted in other cities for which old insect collections are available.

Finally, although comparative analyses regarding insects are still lacking, it would be interesting to investigate in the future the parameters of the species-area relationship in relation to taxon ecology. The species-area relationship is usually modelled by the power function $S=C A^{z}$ (Triantis and Bhagwat, 2011), which can be linearized in the double logarithmic form $\log S=\log C+z \log A$, where $S$ is the number of species, $A$ is the "island area", $C$ is the intercept, and $z$ the slope. In the case of urban green spaces, the slope should be lower as immigration rates, the number of transient species, and the importance of rescue effects increase. Because these factors are in turn related to distance between green spaces and to matrix permeability, the degree of isolation should affect the shape of the species-area relationship.

Acknowledgements. I am grateful to P. A. V. Borges and one anonymous referee for their useful suggestions.

Edited by: J. Stadler

Reviewed by: P. Borges and J. Röder

\section{References}

Adler, F. R. and Tanner, C. J.: Urban Ecosystems, Cambridge University Press, Cambridge, 353 pp., 2013.

Angold, P. G., Sadler, J. P., Hill, M. O., Pullin, A., Rushton, S., Austin, K., Small, E., Wood, B., Wadsworth, R., Sanderson, R., and Thompson, K.: Biodiversity in urban habitat patches, Sci. Total. Environ., 360, 196-204, 2006.

Blair, R. B.: Birds and butterflies along an urban gradient: surrogate taxa for assessing biodiversity?, Ecol. Appl., 9, 164-170, 1999.

Bolger, D. T., Suarez, A. V., Crooks, K. R., Morrison, S. A., and Case, T. J.: Arthropods in urban habitat fragments in southern California: area, age and edge effects, Ecol. Appl., 10, 12301248, 2000.

Croci, S., Butet, A., Georges, A., Aguejdad, R., and Clergeau, P.: Small urban woodlands as biodiversity conservation hot spot: a multi-taxon approach, Ladsc. Ecol., 23, 1171-1186, 2008.

Davis, B. N. K.: The ground arthropods of London gardens, London Nat., 58, 15-24, 1979.

Faeth, S. H. and Kane, T. C.: Urban biogeography: City parks as islands for Diptera and Coleoptera, Oecologia, 32, 127-133, 1978.

Fattorini, S.: Insect extinction by urbanization: a long term study in Rome, Biol. Conserv., 144, 370-375, 2011a.

Fattorini, S.: Insect rarity, extinction and conservation in urban Rome (Italy): a 120-year-long study of tenebrionid beetles, Insect Conserv. Diver., 4, 307-315, 2011 b.

Fattorini, S.: Species ecological preferences predict extinction risk in urban tenebrionid beetle guilds, Anim. Biol., 63, 93-106, 2013.

Fattorini, S.: Island biogeography of urban insects: Tenebrionid beetles from Rome tell a different story, J. Insect. Conserv., 18, 729735, 2014a.

Fattorini, S.: Urban biodiversity hotspots are not related to the structure of green spaces: a case study of tenebrionid beetles from Rome, Italy, Urban Ecosyst., 17, 1033-1045, 2014 b.

Fattorini, S., Dapporto L., Strona, G., and Borges, P. A. V.: Calling for a new strategy to measure environmental (habitat) diversity in Island Biogeography: a case study of Mediterranean tenebrionids (Coleoptera: Tenebrionidae), Fragmenta entomol., 47, 1-14, 2015.

Godefroid, S. and Koedam, N.: How important are large vs. small forest remnants for the conservation of the woodland flora in an urban context?. Global Ecol. Biogeogr., 12, 287-298, 2003.

Hardy, P. B. and Dennis, R. L. H.: The impact of urban development on butterflies within a city region, Biodiv. Conserv., 8, 12611279, 1999.

Jones, E. L. and Leather, S. R.: Invertebrates in urban areas: A review, Eur. J. Entomol., 109, 463-478, 2012.

Knapp, S., Kuhn, I., Mosbrugger, V. and Klotz, S.: Do protected areas in urban and rural landscapes differ in species diversity?, Biodiv. Conserv., 17, 1595-1612, 2008.

Koivula, M. J. and Vermeulen, H. J. W.: Highways and forest fragmentation - effects on carabid beetles (Coleoptera, Carabidae), Landsc. Ecol., 20, 911-926, 2005.

Konvicka, M. and Kadlec, T. How to increase the value of urban areas for butterfly conservation? A lesson from Prague nature reserves and parks, Eur. J. Entomol., 108, 219-229, 2011.

Kotze, D. J., Lehvävirta, S., Koivula, M., O’Hara, R. B., and Spence, J. R.: Effects of habitat edges and trampling on the dis- 
tribution of ground beetles (Coleoptera, Carabidae) in urban forests, J. Insect. Conserv., 16, 883-897, 2012.

Magura, T., Tóthmérés, B., and Molnár, T: Forest edge and diversity: carabids along forest-grassland transects, Biodivers. Conserv., 10, 287-300, 2001.

Murgui, E.: Effects of seasonality on the species-area relationship: a case study with birds in urban parks, Global Ecol. Biogeogr., 16, 319-329, 2007.

Miyashita, T., Shinkai, A., and Chida, T.: The effects of forest fragmentation on web spider communities in urban areas, Biol. Conserv., 86, 357-364, 1998.

Parker, S.: Small reserves can successfully preserve rare plants despite management challenges, Nat. Area. J., 32, 403-411, 2012.

Saarinen, K., Valtonen, A., Jantunen, J., and Saarnio, S.: Butterflies and diurnal moths along road verges: Does road type affect diversity and abundance?, Biol. Conserv., 123, 403-412, 2005.

Sadler, J. P., Small, E. C., Fiszpan, H., Telfer, M. G., and Niemelä, J.: Investigating environmental variation and landscape characteristics of an urban-rural gradient using woodland carabid assemblages, J. Biogeogr., 33, 1126-1138, 2006.
Sisk, T. D., Haddad, N. M., and Ehrlich, P. R.: Bird assemblages in patchy woodlands: modeling the effects of edge and matrix habitat, Ecol. Appl., 7, 1170-1180, 1997.

Small, E., Sadler, J. P., and Telfer, M. G.: Do landscape factors affect brownfield carabid assemblages?, Sci. Total Environ, 360, 205222, 2006.

Soga, M., Kanno, N., Yamaura, Y., and Koike, S.: Patch size determines the strength of edge effects on carabid beetle assemblages in urban remnant forests, J. Insect Conserv., 17, 421-428, 2013.

Triantis, K. A. and Bhagwat, S. A.: Applied Island Biogeography, in: Conservation Biogeography, edited by Ladle, R. J. and Whittaker, R. J,. John Wiley \& Sons, Ltd, Chichester, UK, 190-223, 2011.

Weller, B. and Ganzhorn, J. U.: Carabid beetle community composition, body size, and fluctuating asymmetry along an urban-rural gradient, Basic Appl. Ecol., 5, 193-201, 2004.

Yamaura, Y., Kawahara, T., Lida, S., and Ozaki, K.: Relative importance of the area and shape of patches to the diversity of multiple taxa, Conserv. Biol., 22, 1513-1522, 2008. 